\title{
IMPACT OF LOCKDOWN ON THE TRAINING PROCESS AND RANKING IN TAEKWONDO ITF COMPETITIONS DURING A PANDEMIC
}

\author{
Silvia Ilieva-Sinigerova \\ National Sports Academy "Vassil Levski” (Bulgaria)
}

\begin{abstract}
The last year of the global COVID-19 pandemic has provoked unprecedented countermeasures in all sectors of the economy, including individual, group, institutional and industrial. The sports industry suddenly stopped all events.

The aim of the present study was to evaluate the effect of the introduced emergency measures in Bulgaria on the training process and the performance of taekwondo ITF athletes in the discipline "pattern" of the state online championship in 2020 .

The study was conducted in the period 27/04-10/05/2020 and involved 79 athletes, profiled as representatives of large cities (Sofia, Plovdiv, Varna) $27.8 \%$ and $72.2 \%$ - of small cities. The division was provoked by the various measures that were imposed during the state of emergency. The survey was conducted through an Internet-based questionnaire, which contains 23 items related to the training process during the state of emergency, as well as the ranking of the competitors in the online championship. The analysis made were the following: alternative analysis (to establish the relative shares of different responses in the questionnaires), comparative analysis ( $\mathrm{U}$ - criteria of Mann Whitney), Varimax factor analysis and Hierarchical cluster analysis (Ward's method).

Statistically significant differences was found in the conducted training for equipment, in which in the big cities $4-5$ times a week the athletes did not train, while in the small ones $-3.5 \%$. The largest number of trainees conducted $1-2$ training sessions a week. In the big cities it ranked second 3 times a week, while in the small cities - I have not trained. It was noteworthy that the representatives of the big cities evaluate the sharing of video trainings positively, while in the small cities they were hesitant in their opinion and the competitors indicate different evaluations.

The key individual work of the coach with the medalists in both types of settlements stood out. There was a small number of trainings for medalists, which were systematized and focused. In 5th-8th place, a larger number of trainings was
\end{abstract}


established, but the assistance from the coach was missing. There was a lack of motivation in not medalist athletes.

Keywords: COVID-19; pandemic; online competitions; taekwondo

\section{Introduction}

The last year of the global COVID-19 pandemic has provoked unprecedented countermeasures in all sectors of the economy, including individual, group, institutional and industrial. The sports industry suddenly stopped all events. The COVID-19 outbreak that started in mid-December 2019 in Wuhan (China) had already infected more than 3.2 million people in the world in early May 2020 (Jose Miguel et al. 2020). Many countries around the world had to impose restrictive measures which had affected thousands of million people due to the high rate of propagation and contagion as well as to the difficulty to control it. By the end of March 2020, more than 100 countries ordered the total or partial closure of their borders and restricted the movement of people to strictly necessary reasons of food supply, work and health (Lazzerini \& Putoto 2020).

Starting on 9 March 2020 Italy ordered the implementation of physical distancing measures. Schools and many other recreational, cultural, and sports centers must stay closed in order to avoid human-to-human transmission (Cagno et al. 2020). To safeguard the health of athletes and others involved, the Olympics and Paralympics events, as well as other sports competitions at international, national, and regional levels, had been postponed to 2021 or erased. Until 4 May 2020, quarantine measures kept a large number of people in isolation, restricting their activity practice and interactions, with significant psychological effects on individuals and societies (Cagno et al. 2020). Two lockdowns had been introduced, one from 23 March to 1 June, and another from 5 November to earlyDecember, 2020 for UK citizens (as for citizens of most high infection countries) such lockdown measures had included the closure of indoor public spaces, such as restaurants, bars, gyms, leisure centers and 'non-essential shops'. The cancelling of events, such as weddings and festivals, and the national order that people should only leave their homes for 'limited reasons', such as for 'essential food shopping, exercise once per day, medical need and travelling for work when absolutely necessary' (Grix et al. 2020).

The COVID-19 pandemic has had, and will continue to have effects on people's physical and mental well-being all around the world, also on athletes and sporting world. Children, adolescent, and adult athletes demonstrated different stress reactions to their sport activity break. Nevertheless, if adequately supported by social connections, including their teammates and coaches, and their sport environment, they could successfully address the distress condition (Cagno et al. 2020).

Bulgaria, like most high-risk countries, has gone through several lockdowns. The sports world (like everyone else) turned out to be unprepared for the upcoming 
situation. The fear that provoked the unknown was great. Each country had imposed different restrictions on its residents. However, in addition to the people in Bulgaria, various restrictive measures had been applied in large and small settlements. Compliance with the measures varied from city to city. In the period $6-8.03$ in Panagyurishte (282 participants) was held the state taekwondo championship ITF in several disciplines, one of which is "pattern". As of March 13, measures were imposed by which the state literally "froze" in anticipation. Complete impossibility to conduct a normal and effective training process. Complete impossibility for a normal life. Without clarity how long all this will last.

On April 26, the Bulgarian Taekwondo Federation ITF held a state online championship in the discipline "pattern", in which 79 athletes from different sports clubs, of different ages, sports experience and qualifications participated. Various measures were taken until this championship was held online - online training through different platforms (zoom, messenger, google meet, etc.), individual training programs and sharing training videos (YouTube channels).

\section{Purpose}

The aim of the present study was to evaluate the effect of the introduced emergency measures in Bulgaria on the training process and the performance of taekwondo ITF athletes in the discipline "pattern" of the state online championship in 2020 .

\section{Methodology}

The study was conducted in the period 27/04 - 10/05/2020 and involved 79 athletes, profiled as representatives of large cities (Sofia, Plovdiv, Varna) - 27.8\% and $72.2 \%$ - of small cities. The division was provoked by the various measures that were imposed during the state of emergenc. The survey was conducted through an Internet-based questionnaire, which contains 23 items related to the training process during the state of emergency, as well as the ranking of the competitors in the online championship. Three types of questions were used - alternative, with more than one answer and a five-point Likert Scale. The evaluation was given from 1 to 5 points, where 1 is strongly positive and 5 is strongly negative.

\section{Methods}

In order to fulfill the aim of the research we used online-based survey. The questions were aimed at getting feedback from athletes after online competitions and the impact by the pandemic.

\section{Statistical Analysis}

The software package used to analyze the final data from the research was SPSS 25.0. The analysis made were the following: alternative analysis (to establish the 
relative shares of different responses in the questionnaires), comparative analysis ( $\mathrm{U}$ - criteria of Mann Whitney), Varimax factor analysis and Hierarchical cluster analysis (Ward's method).

\section{Results}

The questions were divided into four large groups and cover: training process, assistance from the coach, communication and recovery and motivation.

The first group was generally related to the training process. Given the fact that it was performed without the supervision of a sports specialist, the questions were asked about the number of training sessions per week. There was a division into the number of training sessions for technical elements and the number of training sessions for GPT (general physical training), in order to be able to differentiate what the athletes trained for. Training for GPT can be held anywhere, while training for technical elements required a lot of free space and given the closing and conduct of classes at home, not everyone has had such an opportunity.

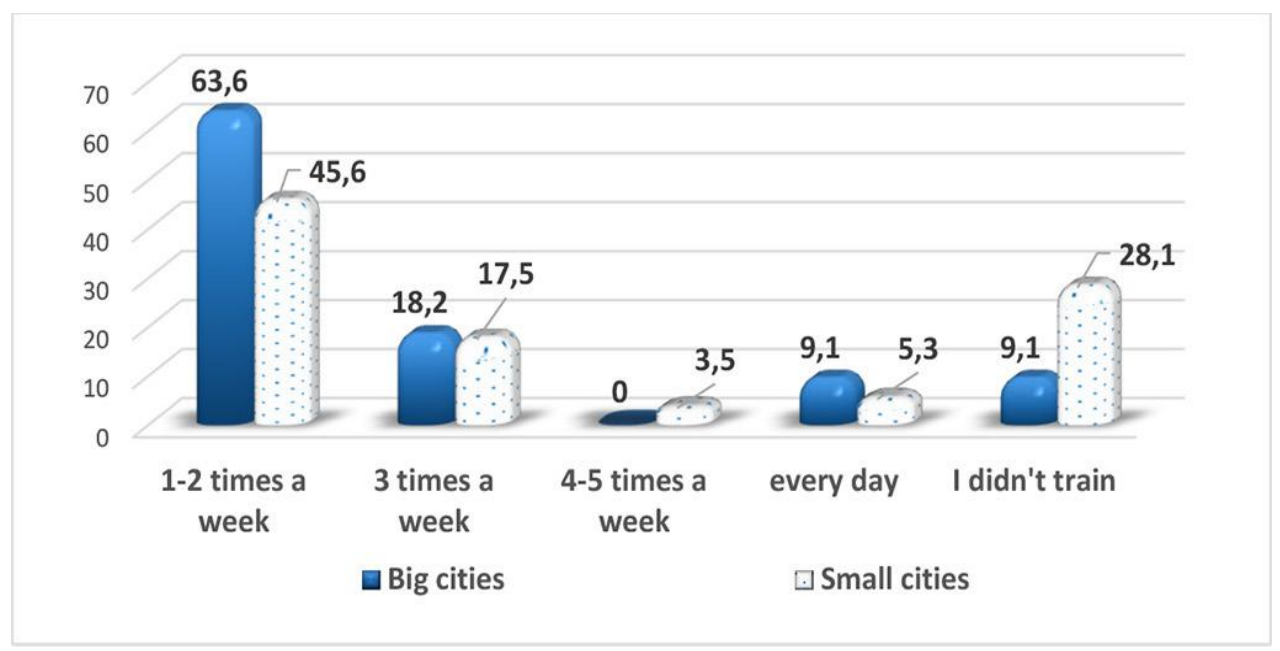

Figure 1. How often did you train technical elements during the lockdown?

Statistically significant differences were found in the conducted trainings for technical elements, in which in the big cities 4-5 times a week no one trained, while in the small ones $-3.5 \%$. The largest number of trainees conducted $1-2$ training sessions a week. In the big cities it ranks second 3 times a week, while in the small cities - I have not trained. 


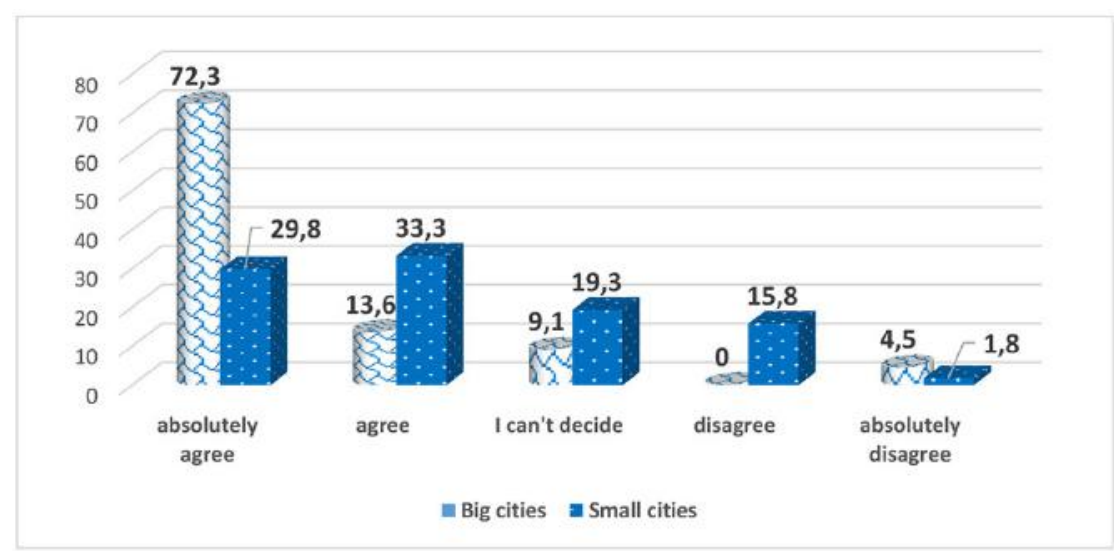

Figure 2. The coach conducted useful video trainings

Coach assistance was the second major group of factors. Various aspects of coaching work that may affect the training of athletes were covered. Statistically significant differences were found between the responses in conducting video training, which were useful. Note that the representatives of the big cities evaluated the sharing of video trainings positively $(85.9 \%)$, while in the small cities were hesitant in their opinion and the competitors had given different evaluations.

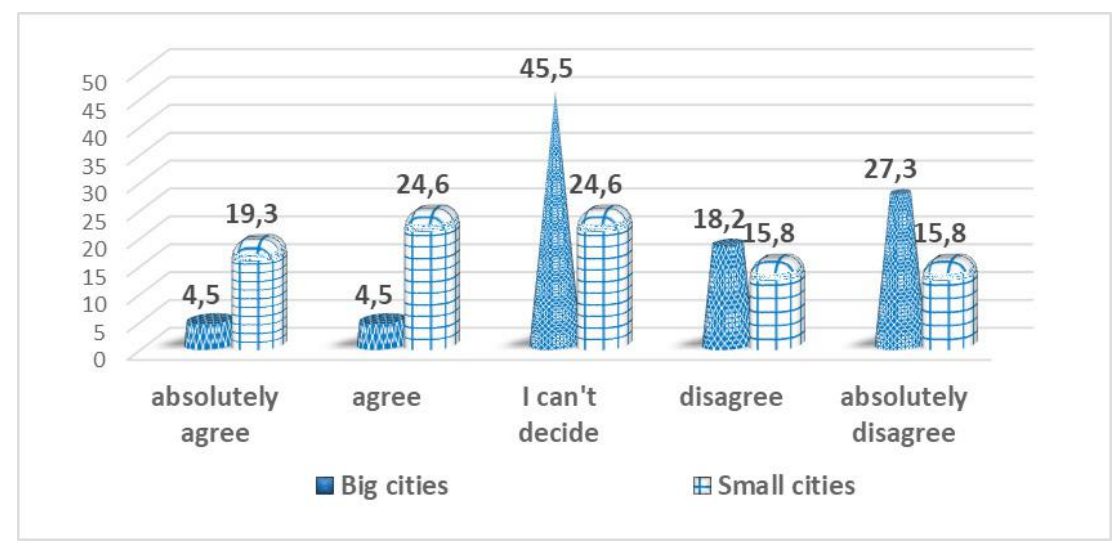

Figure 3. I did not feel the limitations because of school distance learning

Lack of communication and ability to recover was the next group related to how the athletes accept the imposed isolation and whether they used the time for rest and recovery. Statistically significant differences were found in the question "I did not 
feel the limitations due to distance learning at school." In this matter, the differences between the representatives of large and small cities were very clear. Athletes from big cities did not agree and had actually felt the limitations of the measures (45.5\%), despite distance learning. Competitors from small towns were at the other extreme - they rather agree that they had not felt the restrictions due to distance learning at school (43.9\%). Athletes from large cities who hesitate in their assessments were $45.5 \%$, while representatives of small cities who chose this answer were $24.6 \%$.

Table 1. Comparative analysis between athletes' assessments

by the place of residence

\begin{tabular}{|l|l|l|l|}
\hline & $\begin{array}{l}\text { How often did } \\
\text { you train } \\
\text { technical ele- } \\
\text { ments? }\end{array}$ & $\begin{array}{l}\text { The coach } \\
\text { conducted } \\
\text { useful video } \\
\text { trainings? }\end{array}$ & $\begin{array}{l}\text { I didn't feel the } \\
\text { limitations } \\
\text { because of school } \\
\text { distance learning! }\end{array}$ \\
\hline Mann-Whitney U & 455.500 & 355.000 & 421.500 \\
\hline Wilcoxon W & 2108.500 & 608.000 & 2074.500 \\
\hline Z & -1.919 & -3.136 & -2.305 \\
\hline $\begin{array}{l}\text { Asymp.Sig. } \\
\text { (2-tailed) }\end{array}$ & .049 & .002 & .021 \\
\hline
\end{tabular}

The comparative analysis of the results along the factor place of resistance among the indicators could assumed that there were statistically significant differences in these three questions between the responses of the competitors.

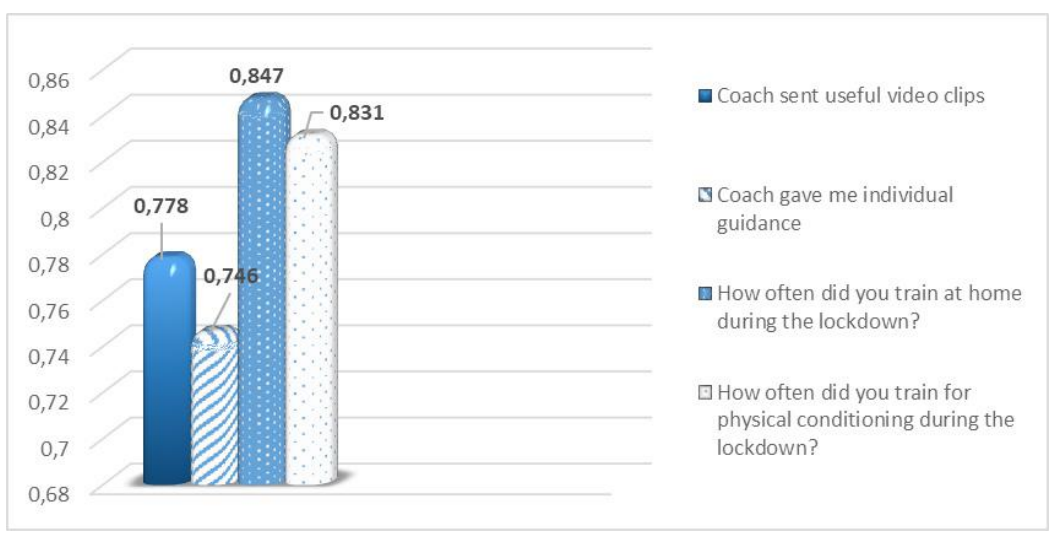

Figure 4. Factor structure of the $1^{\text {st }}$ group of factors

The first factor in the factor structure of the training process and coach's assistance was determined by two main indexes and had explained $31.25 \%$ of the 
initial dispersion of the researched phenomenon. The indexes that determined this factor were useful video clips and individual guidance. This factor can defined as appropriate training materials and individual coach's work. The second factor in the factor structure of the training process and coach's assistance determined by two main indexes and had explained $21.59 \%$ of the initial dispersion of the researched phenomenon. This factor can defined as number of training sessions. These had a higher factor weight, which was evident from the figure 4.

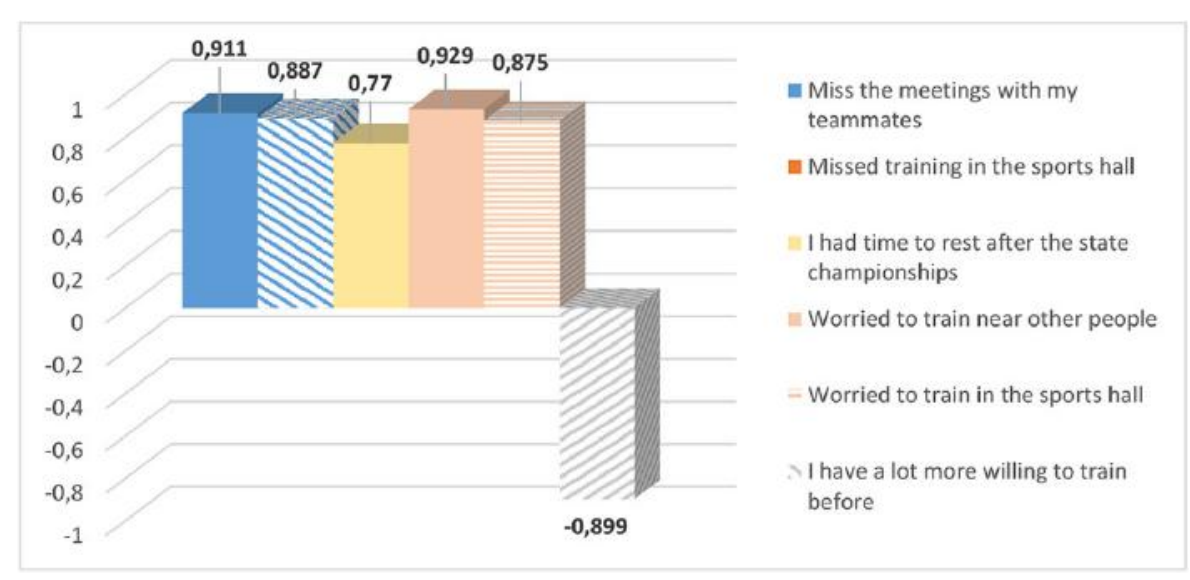

Figure 5. Factor structure of the $2^{\text {nd }}$ and $3^{\text {rd }}$ groups of factors

The first factor in the factor structure of the lack of communication and recovery was determined by two main indexes and had explained $32.22 \%$ of the initial dispersion of the researched phenomenon. Nostalgia for teammates and training in the sports hall determined this factor. This factor can defined as live communication. The second factor in the factor structure of the lack of communication and recovery was determined by one main index and had explained $25.50 \%$ of the initial dispersion of the researched phenomenon. Necessary and well-deserved rest after the state championships was established as an important and independent factor. This factor can defined as recovery.

The first factor in the factor structure of the motivation was determined by two main indexes and had explained $46.25 \%$ of the initial dispersion of the researched phenomenon. Also, this factor had the highest explained variance of all factors in the three groups. Anxiety, fear and caution caused by the unknown and imposed social isolation were important factors. This factor can defined as fear and caution. The second factor in the factor structure of the motivation was determined by one main index and had explained $26.88 \%$ of the initial dispersion of the researched phenomenon. This factor can defined as motivation. 
In this way, the number of factors that would be included in the cluster analysis was reduced, and those with the highest factor weight were extracted.

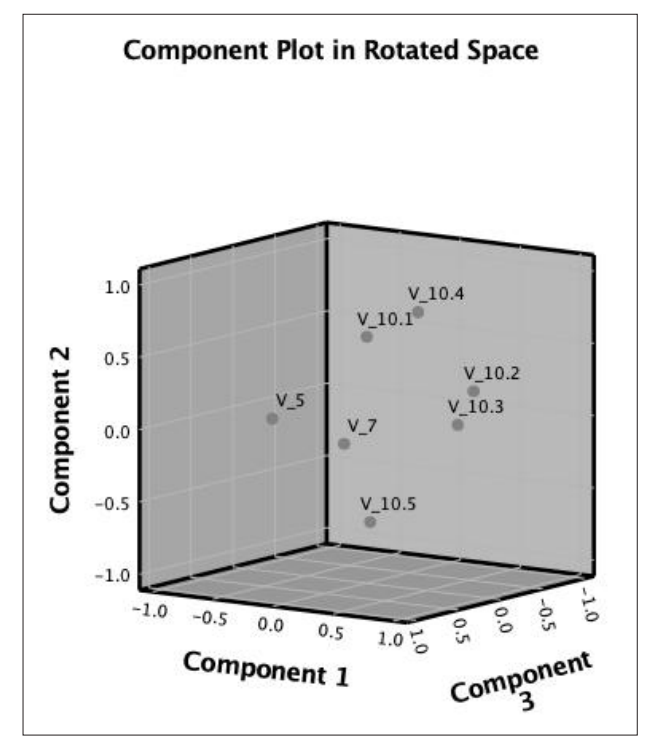

Figure 6. Components of factor analysis

To perform the cluster analysis, the competitors were divided into large and small cities and wanted to see how the factors that have the greatest factor weight affected the ranking in the online championship.

In the big cities noticed that the best ranking was 2 nd place. Found that the individual work of the coach with these athletes (proper training program, individual guidance and training videos) have had a great impact. The number of training sessions was small, on the other hand, they were obviously correctly selected. Noticed that the lack of live communication and nostalgia for teammates and live training in the gym also had an impact. Competitors report great motivation and a strong desire to train. In the bronze medalists, again noticed the significant role of the coach, his guidance and drawing up a proper training program, had contributed to the prize ranking. The number of training sessions was again not large, but obviously, they were selected properly. Unlike the silver medalists, these athletes recovered after the previous competitions and then started the training process again. The role of the coach was not clarified for the competitors with 5-8th place ranking and he did not appear as a key factor for them. Can summarized that these highly motivated athletes who feel a great lack of live contact and communication with teammates and training, but did not worry about the proximity of other people. 
In contrast, among the athletes with a ranking of 9th-17th place stood out the lack of individual work with the coach (proper training program and guidance). There was a larger number of completed trainings, but they were obviously composed only of the level of knowledge of the respective athlete. And again, the lack of live contact and worry about the closeness of other people. It was impressived that these athletes lack strong motivation for training. The lack of support from the coach and the final ranking had contributed to the reduction of the desire for training.

In the clusters of athletes from small towns, the role of the coach stood out among the medalists. In 1st and 2nd place with individual guidance and training videos, while in 3rd place found only the shared videos. The trainings for technical elements were again $1-2$ a week, but in the 2nd place for GPT the athletes had trained 4-5 times a week. Once again, the 3rd place winners took the opportunity to rest after the state championships, after which they started training for the new competition.

At $5^{\text {th }}-8$ th place and $9^{\text {th }}-17$ th place did not find the role of the coach in any form. The difference that was observed was only between the number of training sessions. Without the help of the coaches, the athletes themselves decided what, when, how and how often to train. But at $5-8$ place observed conducted trainings for equipment and GPT, while at $9^{\text {th }}-17$ th place - only trainings for technical elements.

\section{Discussion}

How would the return to the training and competition process after the COVID-19 lockdowns go? Some authors thought that PCR tests should be performed on all football players participating in the competition. The tests should be carried out continuously along with the competition, with the optimum scenario being one test per day. It is necessary that the players try to limit their social contacts as much as possible, and that their physical interaction with the technical staff is as distant as possible (Buldu et al. 2020). Moreover, athletes in this period may experience progressive loss of sport-specific physical fitness, which will result in injury risks when they return to training.

Others (Sarto et al. 2020) are still unsure when and how to restart championships and events, but advised to consider the impact that choices could have on injury risk in elite athletes. In this case, a prolonged pre-season would be warranted to allow full resurgence of athletes' physiological and mental function and performance. With this perspective, aim to recommended extreme caution in sports programming after the COVID-19 emergency and advised to involve all stakeholders in the decisions (e.g. medical staff, head of performance, coaches, fitness trainers and players).

Social contact, even if with distancing, could be an effective "buffer" for psychological distress and could help to have a good resilience (Cagno et al. 2020). Contrariwise, prolonged inactivity, boredom, lack of social interactions with teammates and coaches, may represent stressors; in particular for children and adolescents, adding up to the possible negative effects caused by the pandemic 
and the interruption of the normal training routines (Lim, Pranata 2020). Sedentary attitude, due to lockdown, led to negative effects on children and adolescents, such as mental swings, depression, decrease of general health (Merkel 2013).

The differences among geographic areas responders were not statistically significant, although different levels of epidemic risks were identified. It was previously stated that participants living in more affected geographic areas showed higher scores of stress, because of quarantine or infection (Rossi et al. 2020). However, since the quarantine measures have been the same throughout Italy the sample did not show different psychological reactions. Nevertheless, the low participation of North Italy athletes, the most COVID-19 affected area, could indicate that they may not be willing to participate in the questionnaire survey (Zhou et al. 2020).

\section{Conclusions}

The implemented measures have had different effects in large and small settlements. There was a difference in caution, close contact with other people and training in the sports hall. There was a difference in the number of training sessions conducted between large and small cities, which was influenced by the different compliance with the restrictive measures that were imposed. Over $75 \%$ of athletes were highly motivated and willing to train in the gym, while $15 \%$ of athletes were worried about being close to other people and training in the sports hall. Believed that the coaches, who tried to carry out the training process in some form, acted adequately and were positively evaluated by their athletes.

The lack of normal live communication was an important factor that had a negative impact on athletes. The factors that have had a significant impact on the performance of the athletes are: individual work with the coach; number of conducted trainings; shared training materials; live communication; recovery; fear and caution and strong motivation. The key individual work of the coach with the medalists in both types of settlements stood out.

There was a small number of trainings for medalists, which were systematized and focused. In 5th-8th place, a larger number of trainings was established, but the assistance from the coach was missing. There was a lack of motivation in not medalist athletes.

\section{REFERENCES}

Buldu, J., et al., 2020. The resumption of sports competitions after COVID-19 lockdown: The case of the Spanish football league. Chaos, Solitons \& Fractals [online]. 138(2), 1 - 7 [viewed 5 May 2021]. Available from: DOI:10.1016/j.chaos.2020.109964

Cagno, A., et al., 2020. Psychological Impact of the Quarantine-Induced Stress during the Coronavirus (COVID-19) Outbreak among Italian Athletes. International Journal of Environmental Research and Public 
Health [online] 17(23), 1 - 13 [viewed 5 May 2021]. Available from: doi. org/10.3390/ijerph17238867.

Grix, J. et al., 2020. The impact of COVID-19 on sport. International Journal of Sport Policy and Politics [online]. 13(1), 1-12 [viewed 15 May 2021]. Available from: doi: 10.1080/19406940.2020.1851285

Jose Miguel, V., et al., 2020. Fan's perspective on professional leagues and sporting events during COVID-19 confinement period. Journal of human sport \& exercise [online]. 16(4), 1 - 12 [viewed 3 May 2021]. Available from: doi:10.14198/jhse.2021.164.07

Lim, A. \& Pranata, R., 2020. Sports activities during any pandemic lockdown. Irish Journal of Medical Science [online]. 190(20), 1 - 5 [viewed 5 May 2021]. Available from: doi: 10.1007/s11845-020-02300-9

Merkel, D., 2013. Youth sport: Positive and negative impact on young athletes. Open Access Journal of Sports Medicine [online]. (4), 151 160 [viewed 5 May 2021]. Available from: doi: 10.2147/OAJSM.S33556

Rossi, R., et al., 2020. COVID-19 Pandemic and lockdown measures impact on mental health among the general population in Italy. Front. Psychiatry [online] (11), 1 - 13, [viewed 10 May 2021]. Available from: doi: $10.3389 /$ fpsyt.2020.00790

Sarto, F., et al., 2020. Impact of Potential Physiological Changes due to COVID-19 Home Confinement on Athlete Health Protection in Elite Sports: a Call for Awareness in Sports Programming. Sports Medicine [online]. (50), 1417 - 1419 [viewed 15 May 2021]. Available from: doi. org/10.1007/s40279-020-01297-6

Wang, C., et al., 2020. Immediate psychological responses and associated factors during the initial stage of the 2019 coronavirus disease (COVID-19) epidemic among the general population in China. International Journal of Environmental Research and Public Health [online]. 17(5), 1 - 25 [viewed 10 May 2021]. Available from: doi.org/10.3390/ijerph17051729 Zhou, S.J et al., 2020. Prevalence and socio-demographic correlates of psychological health problems in Chinese adolescents during the outbreak of COVID-19. European Child \& Adolescent Psychiatry [online] (29), $749-758$ [viewed on 10 May 2021]. Available from: doi.org/10.1007/ s00787-020-01541-4

$\triangle$ Silvia Ilieva-Sinigerova

ORCID iD: 0000-0002-6585-7107

Faculty of Sport

Theory of Sport Department

National Sports Academy "Vassil Levski"

Sofia, Bulgaria

E-mail: nsastatics@gmail.com 